Supporting Information

\title{
Rational design of a rigid fluorophore-molecular rotor-based probe for high signal-to-background ratio detection of sulfur dioxide in viscous system
}

Longwei He, Yunzhen Yang, and Weiying Lin*

Institute of Fluorescent Probes for Biological Imaging, School of Chemistry and Chemical Engineering, School of Materials Science and Engineering, University of Jinan, Shandong 250022, P. R. China

Email: weiyinglin2013@163.com 


\section{Table of contents}

Page

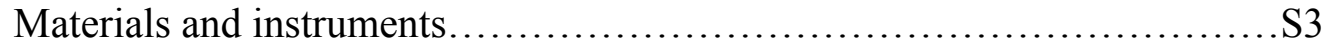

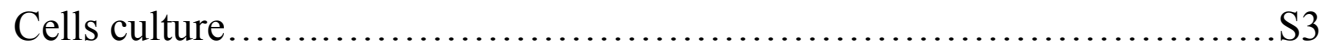

Determination of the fluorescence quantum yield $\ldots \ldots \ldots \ldots \ldots \ldots \ldots \ldots . . \ldots \ldots$

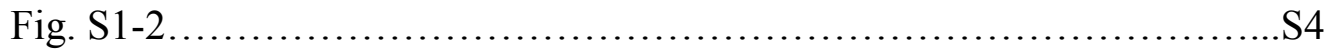

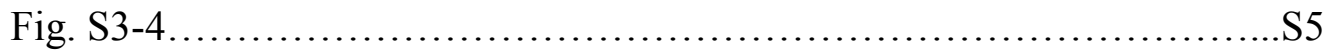

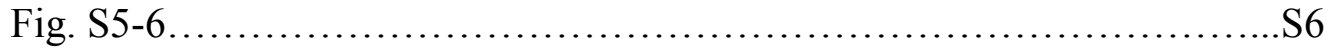

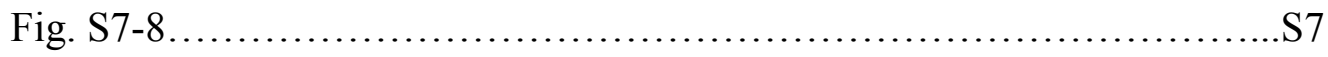

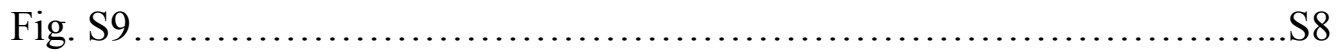

Characterization................................................... 8 -11 
Materials and instruments: Unless otherwise stated, all reagents were purchased from commercial suppliers and used without further purification. Solvents used were purified by standard methods prior to use. Twice-distilled water was used throughout all experiments; The viscosity measurement were carried out on a NDJ-8 rotational viscometer; Mass spectrometric analyses were measured on a Finnigan MAT 95 XP spectrometer; High resolution mass spectrometric (HRMS) analyses were measured on an Agilent $1100 \mathrm{HPLC} / \mathrm{MSD}$ spectrometer; NMR spectra were recorded on an AVANCE III 400 MHz Digital NMR Spectrometer, using TMS as an internal standard; Electronic absorption spectra were obtained on a Shimadzu UV-2700 power spectrometer; Photoluminescent spectra were recorded with a HITACHI F4600 fluorescence spectrophotometer with a $1 \mathrm{~cm}$ standard quartz cell; The fluorescent images of solution and filter paper strip were excited by a $365 \mathrm{~nm}$ lighting of ZF-1 UV analyzer; The fluorescence imaging of cells was performed with a Nikon A1MP confocal microscope; The $\mathrm{pH}$ measurements were carried out on a Mettler-Toledo Delta $320 \mathrm{pH}$ meter; TLC analysis was performed on silica gel plates and column chromatography was conducted over silica gel (mesh 200-300), both of which were obtained from the Qingdao Ocean Chemicals.

Cells culture. HeLa cells were cultured in DMEM (Dulbecco's modified Eagle's medium) supplemented with 10\% FBS (fetal bovine serum) in an atmosphere of 5\% $\mathrm{CO}_{2}$ and $95 \%$ air at $37^{\circ} \mathrm{C}$.

Determination of the fluorescence quantum yield. Fluorescence quantum yield $\left(\Phi_{f}\right)$ was determined by using rhodamine $\mathrm{B}\left(\Phi_{f}=0.31\right.$, in water $)$ as the fluorescence standard. The quantum yield was calculated using the following equation.

$$
\Phi_{F(X)}=\Phi_{F(S)}\left(A_{S} F_{X} / A_{X} F_{S}\right)\left(n_{X} / n_{S}\right)^{2}
$$

Where $\Phi_{F}$ is the fluorescence quantum yield, $A$ is the absorbance at the excitation wavelength, $F$ is the area under the corrected emission curve, and $n$ is the refractive index of the solvent used. Subscripts ${ }_{S}$ and ${ }_{X}$ refer to the standard and to the unknown, respectively. 


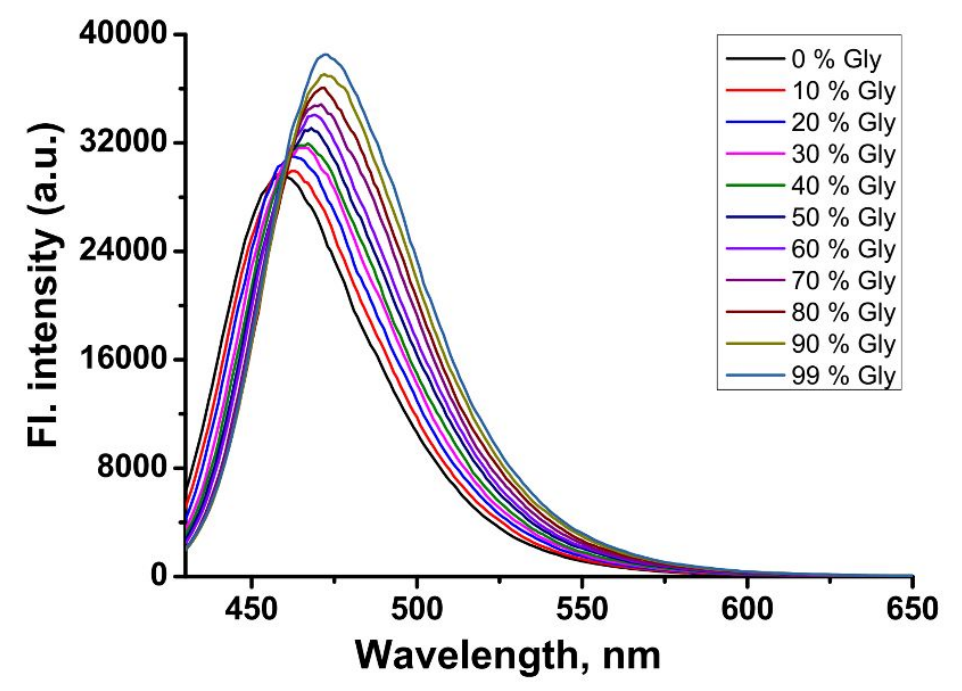

Figure S1. The emission spectra of compound RFC $(10 \mu \mathrm{M})$ in methanol and glycerol mixture with various volume ratios. Excitation at $405 \mathrm{~nm}$.

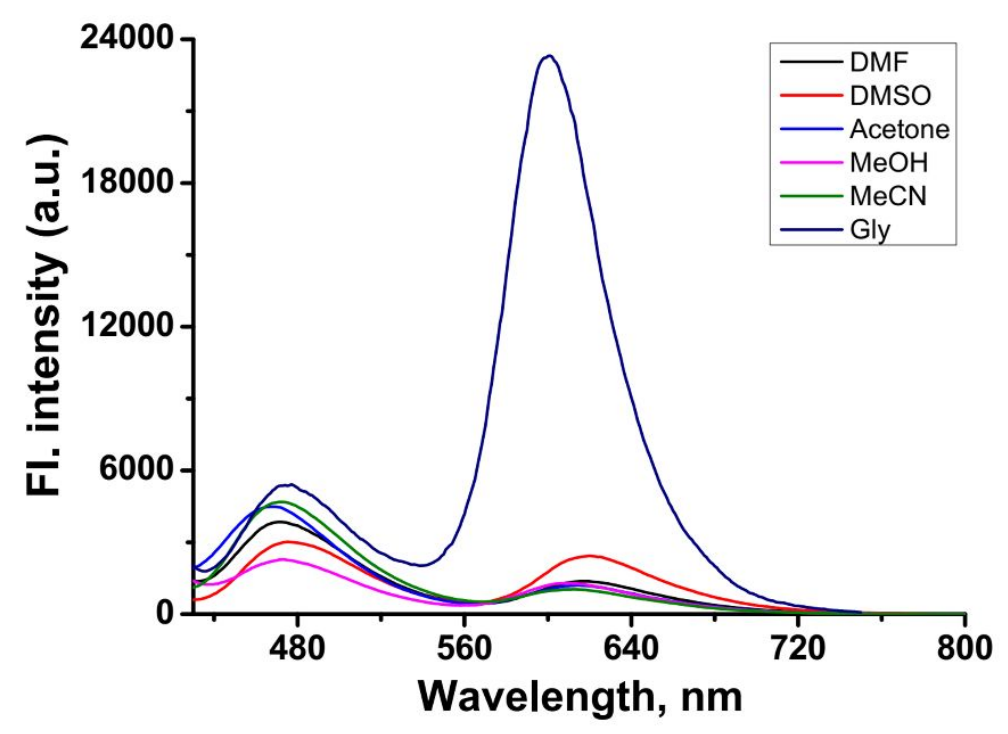

Figure S2. The emission spectra of probe RFC-MRC $(10 \mu \mathrm{M})$ in various water-miscible organic solvents and glycerol. Excitation at $405 \mathrm{~nm}$. 
(A)

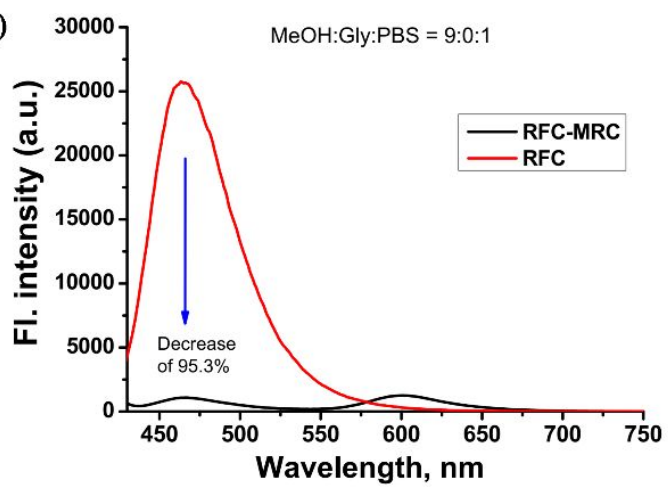

(B)

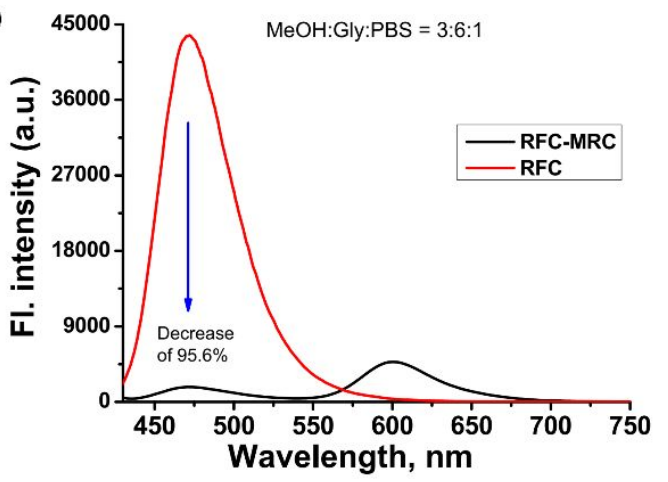

Figure S3. The emission spectra of probe RFC-MRC $(10 \mu \mathrm{M})$ and compound RFC $(10 \mu \mathrm{M})$ in (A) MeOH-PBS buffer (25 mM, pH 7.4) mixture (v/v 9:1) and (B) MeOH-Gly-PBS buffer mixture $(\mathrm{v} / \mathrm{v} / \mathrm{v} 3: 6: 1)$. Excitation at $405 \mathrm{~nm}$.

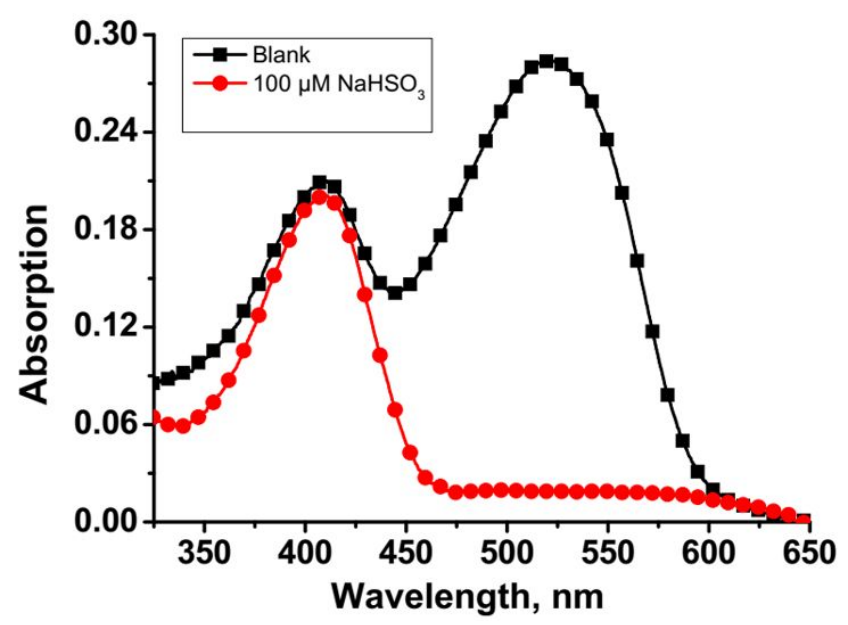

Figure S4. The absorption spectra of probe RFC-MRC $(10 \mu \mathrm{M})$ in the absence or presence of 100 $\mu \mathrm{M} \mathrm{NaHSO} 3$ in methanol, glycerol and PBS buffer $(25 \mathrm{mM}, \mathrm{pH}$ 7.4) mixture with volume ratio $3: 6: 1$. 


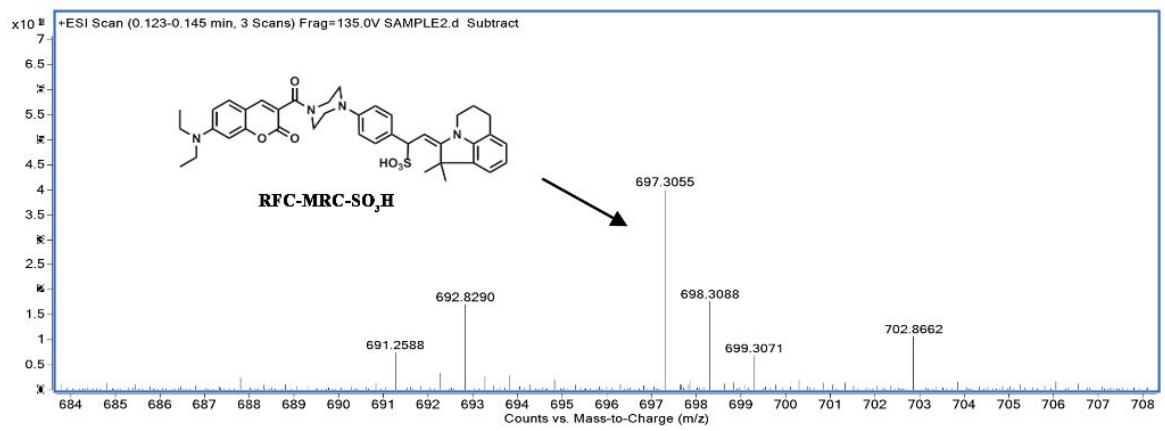

Figure S5. The mass spectrum of probe RFC-MRC in the absence or presence of $\mathrm{NaHSO}_{3}$ in aqueous solution. HRMS (ESI) $m / z$ calcd for compound RFC-MRC-SO $\mathbf{O}_{3} \mathbf{H}\left(\mathrm{C}_{39} \mathrm{H}_{44} \mathrm{~N}_{4} \mathrm{O}_{3}{ }^{+},[\mathrm{M}+\mathrm{H}]^{+}\right)$: 697.3054. Found 697.3055.
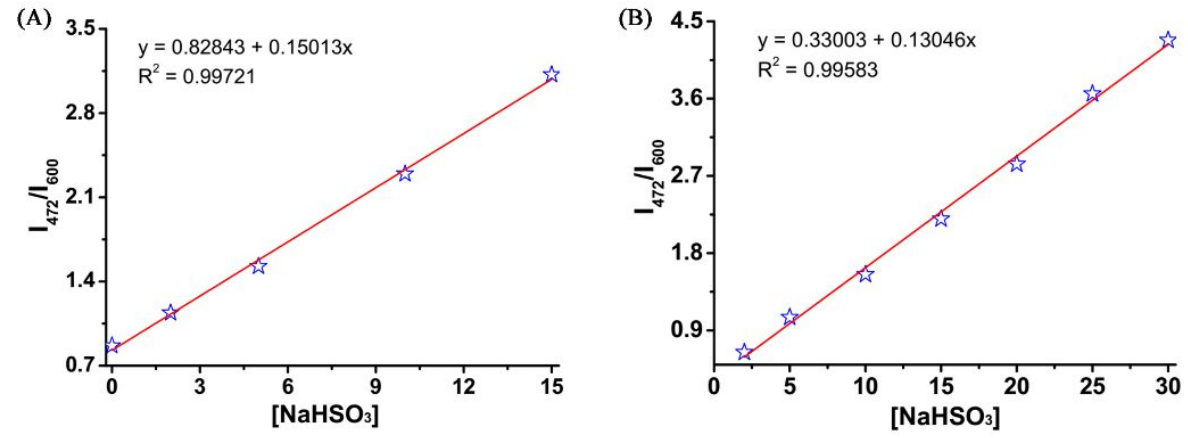

Figure S6. Linear correlation between the ratio values of fluorescence emission intensity $\left(\mathrm{I}_{472} / \mathrm{I}_{600}\right)$ of RFC-MRC (10 $\mu \mathrm{M})$ and $\mathrm{NaHSO}_{3}$ concentration of (A) $0-15 \mu \mathrm{M}$ in methanol and PBS buffer ( $25 \mathrm{mM}, \mathrm{pH}$ 7.4) mixture with volume ratio 9:1 and (B) 2-30 $\mu \mathrm{M}$ in methanol, glycerol and PBS buffer (25 mM, pH 7.4) mixture with volume ratio 3:6:1. 
(A)

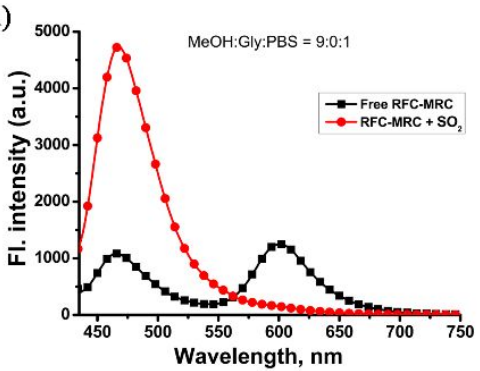

(C) ${ }_{30000}$

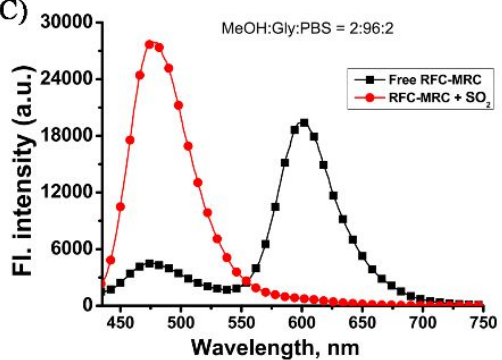

(B)

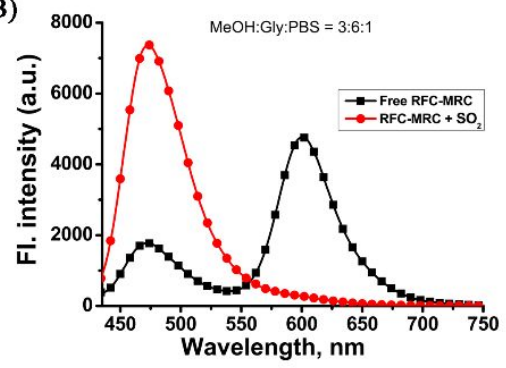

(D)

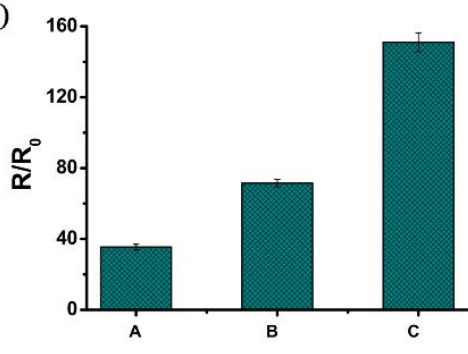

Figure S7. The emission spectra of probe RFC-MRC $(10 \mu \mathrm{M})$ in the absence or presence of $\mathrm{NaHSO}_{3}(100 \mu \mathrm{M}$ ) in (A) MeOH-PBS buffer (25 mM, pH 7.4) mixture (v/v 9:1), (B) MeOH-GlyPBS buffer mixture (v/v/v 3:6:1), and (C) MeOH-Gly-PBS buffer mixture (v/v/v 2:96:2). (D) The increase of ratio signal $\left(\mathrm{I}_{472} / \mathrm{I}_{600}\right)$ in above three situations. Excitation at $405 \mathrm{~nm}$.

(A)

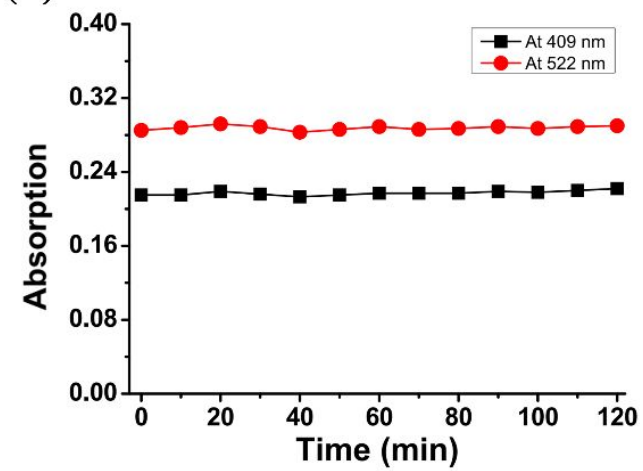

(B)

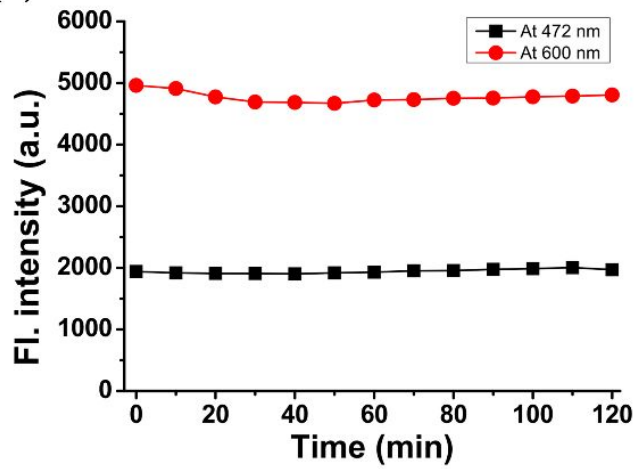

Figure S8. The changes of the absorption of probe RFC-MRC at 409 and $522 \mathrm{~nm}$ in dark (A) and the fluorescence intensity of probe RFC-MRC at 472 and $600 \mathrm{~nm}$ under the constant laser irradiation (B) in MeOH-Gly-PBS buffer (v/v/v 3:6:1) mixture media within 2 hours. Excitation at $405 \mathrm{~nm}$. 


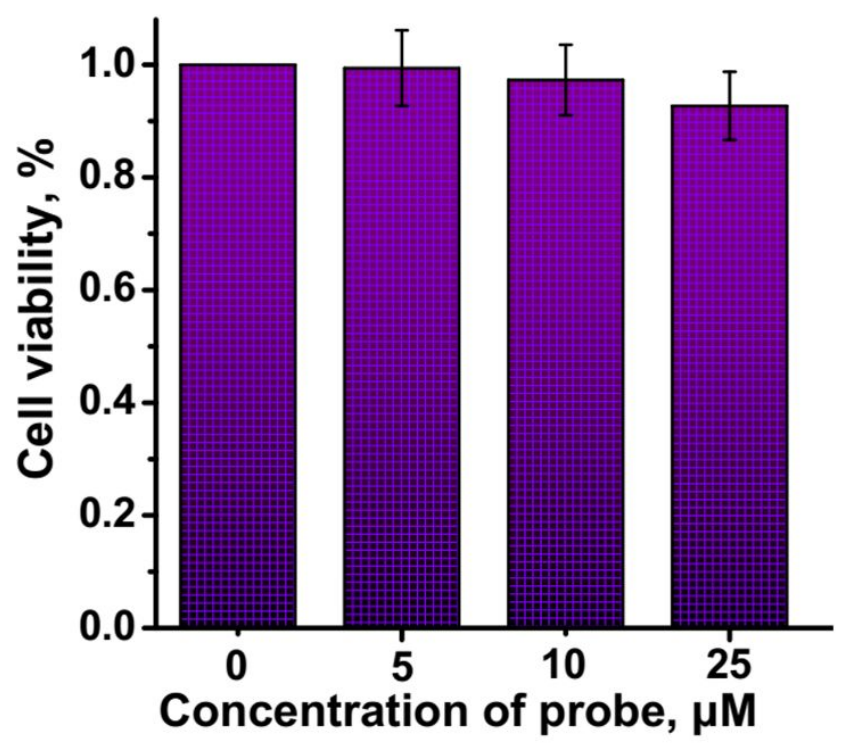

Figure S9. The cell viability of living HeLa cells treated with 5, 10, or $25 \mu \mathrm{M}$ probe RFC-MRC for 24 hours measured by standard MTT assay.

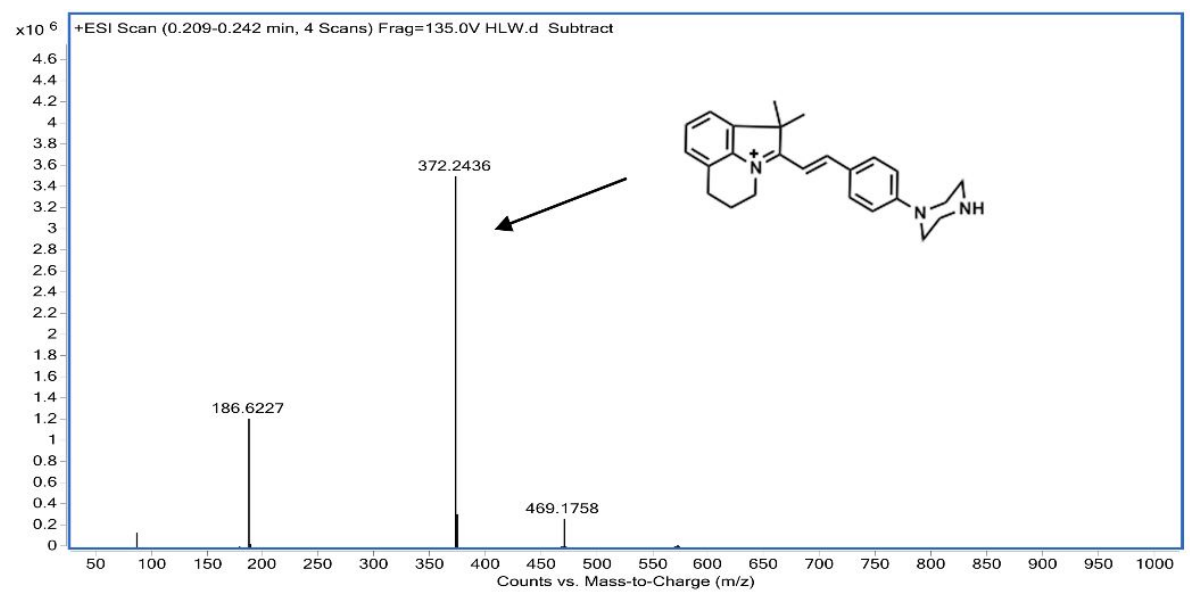

Figure S10. HRMS (ESI) of compound MRC. $m / z$ calcd for $\mathrm{C}_{25} \mathrm{H}_{30} \mathrm{~N}_{3}{ }^{+}\left(\mathrm{M}^{+}\right)$: 372.2434 . Found 372.2436 . 


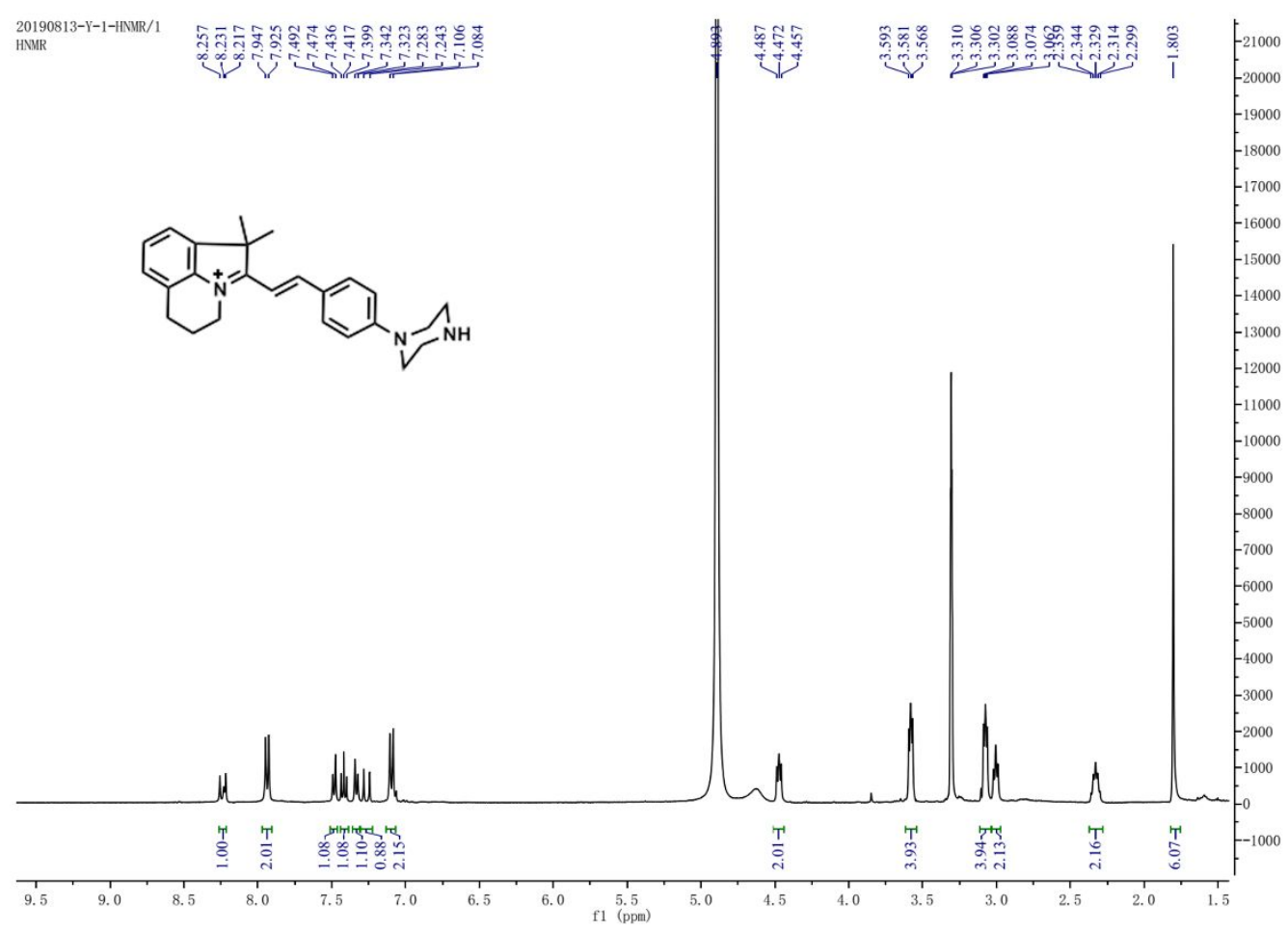

Figure S11. ${ }^{1} \mathrm{H}$ NMR of compound MRC in $\mathrm{CD}_{3} \mathrm{OD}$.

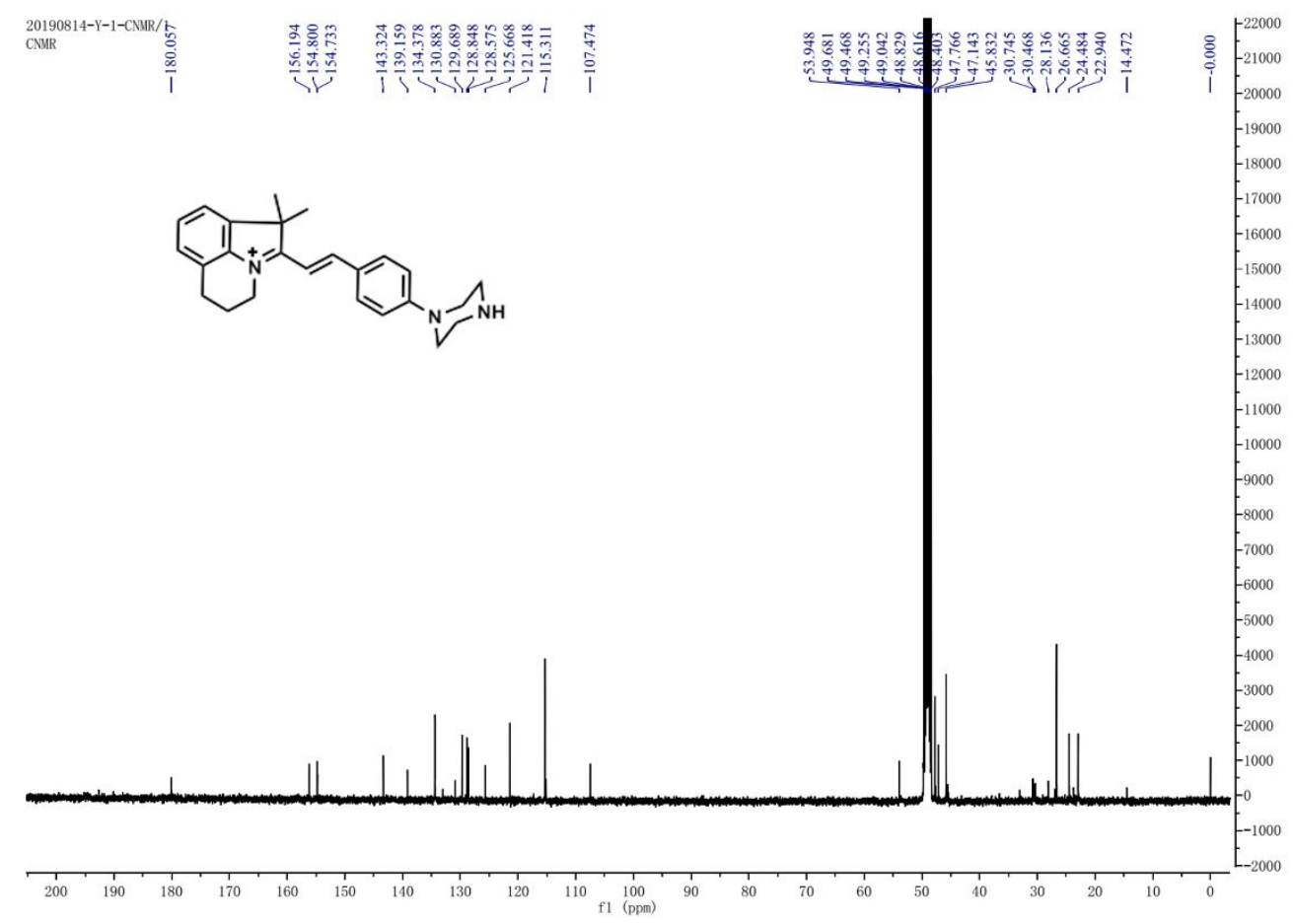

Figure S12. ${ }^{13} \mathrm{C}$ NMR of compound MRC in $\mathrm{CD}_{3} \mathrm{OD}$. 


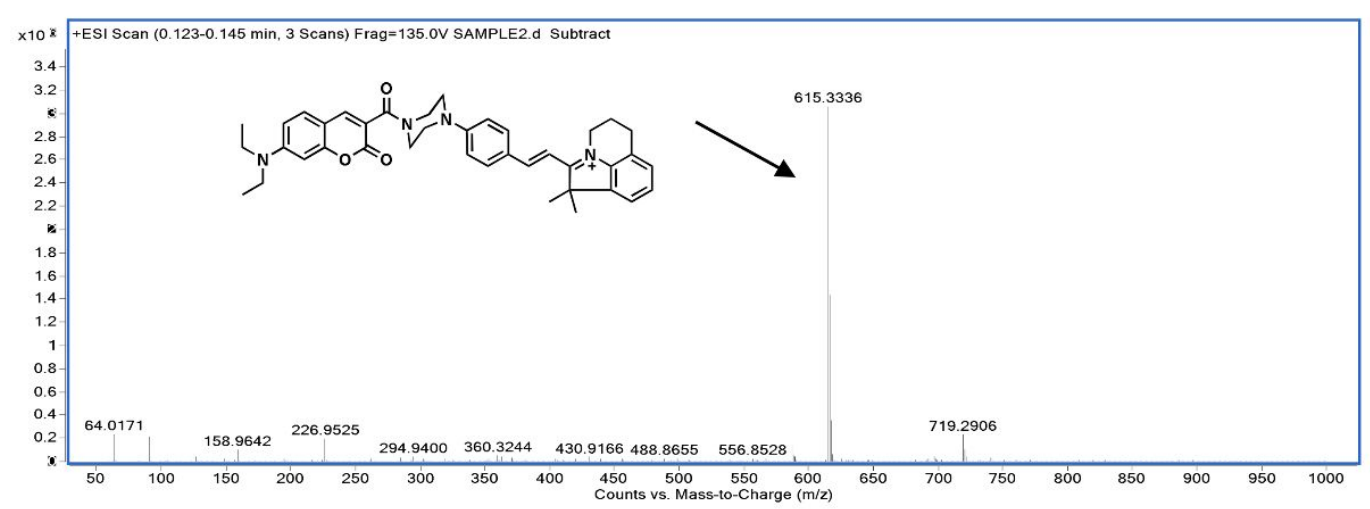

Figure S13. HRMS (ESI) of compound RFC-MRC. $m / z$ calcd for $\mathrm{C}_{39} \mathrm{H}_{43} \mathrm{~N}_{4} \mathrm{O}_{3}{ }^{+}\left(\mathrm{M}^{+}\right)$: 615.3330. Found 615.3336.

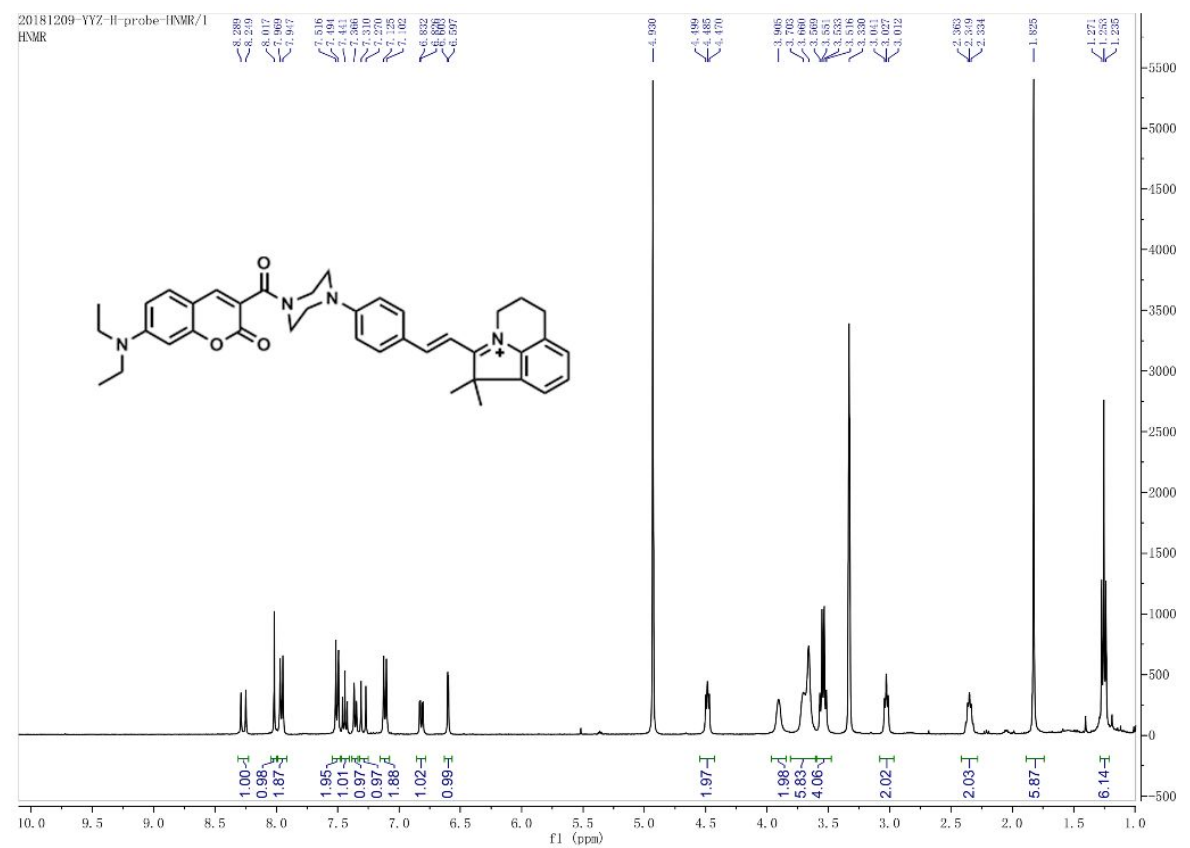

Figure S14. ${ }^{1} \mathrm{H}$ NMR of compound RFC-MRC in $\mathrm{CD}_{3} \mathrm{OD}$. 


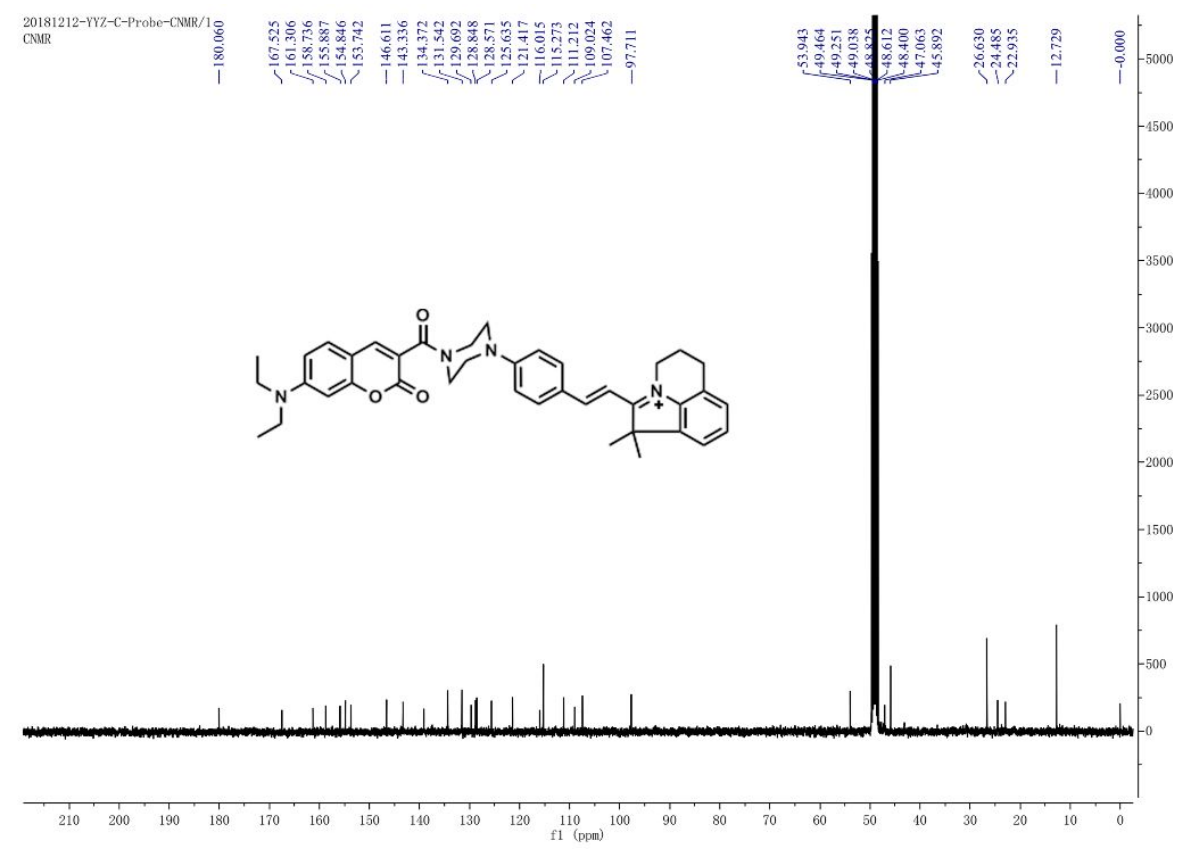

Figure S15. ${ }^{13} \mathrm{C}$ NMR of compound RFC-MRC in $\mathrm{CD}_{3} \mathrm{OD}$. 